andrei kim misc ez reading 2019-20 uni stuff

easy reading for pussies only. u r a pussy ;)

on ekphrasis

on in $\mathrm{C}$

on disney

do the right thing $\quad 9$

vera chytilova

daisies scene analysis

the matrix

platform

night of the living dead

silence

notes on photography 1

notes on photography 2

cindy sherman

non-artist

punctum

precis: controlling darkness

notes on heidegger vs wittgenstein

britney spears critical analysis

on the flea 


\section{On Ekphrasis}

What is really happening when a piece of art is within another? Is it merely citation? Is it representation? Is it interpretation? Is it exploitation?

Both Auden's "Musee des Beaux Arts" and Browning's "My Last Duchess" references paintings within the poem - albeit in different manners, Auden specifically mentions a particular content of a painting - Bruegel's Icarus, whereas Browning explores the effects of a form of a painting - a portrait. The fundamental differences in the manner and the object of reference in these cases calls for a difference in method of approach - what works for one won't for the other. "Musee des Beaux Arts" can serve as a reference point of tracing a specific mythical content and its origins. In this case, a genealogy of this specific myth serves as an exploration of the nature of referentiality, and translations of content from one medium to another. On the other hand, "My Last Duchess" stands on its own, and the poem itself is a ground for observing the different psychological, symbolic, and artistic effects of portrait as a form of painting. In using one poem for tracing a specific content through time, and the other for exploring the effects of a certain artistic form in various manners, there is an unfinished dialectic, where the synthesis leads back to the medium of poetry itself, the medium in which such discussions become possible. In comparing two different methods of deconstruction, the nature of poetry and visual arts as a medium can be shown.

Ovid's Icarus was revered: fishers, shepherds and peasants who "caught sight of" his flight believed that the "creatures who could fly through the air must be gods" 1 . Daedalus and Icarus, differentiated from ordinary people by their abilities to go against natural laws (of gravity), existed in a different realm, out of reach - both literally and figuratively. Ovid's flight was an event, a happening, a story of gaining and losing a supernatural ability. In Bruegel, about fifteen centuries later, lcarus is no longer the focal point of the story: the shepherd and ploughman take the spotlight, Icarus in the water is largely unnoticeable as a supporting character at first glance. The title helps pinpoint Bruegel's intentions: it is supposed to be a "landscape" foremost - along "with the Fall of Icarus". The prominence of Icarus in Bruegel's piece has diminished, along with the grandiosity of the original narrative of Ovid. Auden, then, furthers this process: Bruegel is cited linguistically, in an act of ekphrasis, in the second half of the poem. Within Auden, Bruegel's painting is a coda of sorts, an addition that contextualizes an exploration about the wise fatalism of the aged, that occurs concurrently with nonchalance - "dogs [going] on with their doggy life"2 and "horse [scratching] its innocent behind on a tree"3. For Auden, then, the world of art and myths, and its magic, happens along with the dullness of life: Musee des Beaux Arts "houses" paintings and art objects, not as escapism, but showcasing stories equally as real as, and in the same world as, reality per se. Auden gives new life to Brugehel, who gives new life to Ovid - the act of translation across mediums, is reinterpretation, which brings about preservation, serving as an accompaniment to its antecedent, providing opportunities for revisiting older works. The genealogy itself becomes a story, a particularly western one, where triviality seeps into formerly divine stories: former myths aren't devalued, but merely taken less seriously.

Whereas Auden traced a specific mythical content within a painting, Browning's focus is on painting as form - as metaphor, as a mirror of the possessor, and as an art object with direct effect over people's lives. The portrait lifts the self out of reality and into the illusory symbolic world, where an eternal preservation of the self via an art-object is traded for a

\footnotetext{
1 Ovid. Metamorphoses. Trans. Mary M. Innes, Middlesex: Penguin Books, 1995. Print. 185.

2 Auden, W.H. "Musee des Beaux Arts." The Norton Anthology of English Literature, vol. 2. Gen. ed. Stephen Greenblatt. New York: W.W. Norton and Co., 2012. 2428. Print. 13.

${ }^{3}$ Ibid. 14-15.
} 
gradual loss of the original self. The duchess dies in reality, yet she looks "as if she were alive" 4 "painted on the wall"5. The inefficiency of portrait as form is hinted at: it can "never hope to reproduce"6 absolute reality, but in mimesis get close to it. Mistaking the symbolic world for the real, Browning's narrator masks a self-deficiency in obsessively seeking possession, projecting onto an ideal recreation of the other, not realizing the impossibilities and the illusory nature of such act - in tragedy leading towards murder, when "all smiles stopped together" 7 . In Atwood's short story "My Last Duchess", the main character defends the Duke, calls the Duchess "a half-wit", a "dumb bunny", while her boyfriend believes that the Duke was "a brainer and a show-off" 8 . They eventually break up over the poem: their disagreements in projections over Browning's poem, an art-object, brings up greater discrepancies in their respective irreconcilable worldviews. The underlying sense of fatalism, the inevitability of disagreements between ideal expectations and reality between Atwood's main character and her boyfriend is reminiscent of the relationship between the Duchess and the Duke in Browning's poem. To what extent, then, is Browning's poem rendered "a portrait" for projection for the characters within Atwood's story? Are there sensible lines to draw between the mediums and the corresponding applicability of functions of art, or is it more arbitrary than we think?

Are Auden and Browning, in these two separate cases, attempting something fundamentally different? How does the poet, in each case, make use of language to help us "see" visual art in a new way? Does the poetic response clarify the original piece of art's meaning or does it create alternate meanings?

The dialectic of functions between Auden's preservation of mythical content and Browning's exploration of portrait as form is not necessarily an easy synthesis, but it is more a constant convergence without an easy answer. Auden linguistically cites a visual interpretation of a linguistic mythical story, and Browning explores the psychological and pragmatic effects of portrait as form, rendering the poem itself as an art-object for projection in the process. Auden uses visual art for reinterpreting truths through history, while Browning uses visual art for exploring ontological problems. Is there any way, then, these two approaches can be reconciled? What is there to say about the convergence of discussions of visual form and content within the medium of poetry?

Through poetry, language becomes the medium in which discussions about such higher convergence become possible. Poetry allows for such differences to occur - it elevates discussions out of the realm of ordinary language and gives it new heights and depths. Both Auden and Browning's work have one fundamental commonality: it is, above all, a poetic work - that houses discussions about matters of content and form. The manners in which the two poems discuss these matters are different, but treating "Musee des Beaux Arts" as a thesis and "My Last Duchess" as an antithesis only leads back to the possibilities of the medium of poetry. The richness of language, once found in poems, won't disappear in ordinary language: one can find the very same depths prevalent within what normally isn't considered poetic. The lines become blurred, then, between what can and cannot be poetry: isn't speaking about visual arts itself a poetic act? Can visual arts itself be a poetic act? Is language without visuals possible? Is visuals without language possible?

\footnotetext{
4 Browning, Robert. "My Last Duchess." The Longman Anthology of British Literature, vol. 2. Gen. eds. David Damrosch and Kevin J. H. Dettmar. Boston, MA: Pearson, 2012. 1328. Print. 2.

5 Ibid. 1.

6 lbid. 18.

7 lbid. 46.

${ }^{8}$ Atwood, Margaret. "My Last Duchess." Moral Disorder. Toronto: McClelland \& Stewart. 2006.

Print. 72.
} 
Poetic language invites visual interpretations: Auden demands participation in imagery, and the reader complies by participating within the language. The reader can mentally choose the looks of their "ploughman"9, they get to imagine and reconstruct how "white legs disappearing into the green water"10 would look like. Even knowing nothing about Auden, Bruegel, Icarus, or art history in general, some semblance of such an image would be recreated from the language itself. Special knowledge or skill isn't required to derive a mental image from language - it comes second nature to readers. Inherent within Auden's linguistic interpretation of Bruegel is an unlimited possibility of different visual representations, recreated by each and every reader. Language can be visuals encoded, in which every reader is given an opportunity to decode in their own manner.

In the same manner, visual interpretations invite poetic language: the portrait of the Duchess "seemed as they would ask"11 the Duke "how such a glance came there" 12 . The painter, Fra Pandolf, suggests, with visuals, that "[the Duchess'] mantle laps over my lady's wrist too much"13. In a sense, linguistic representations and interpretation of a visual form is an inherent necessity - translations across mediums, from visual to linguistic, is an essential act through which thoughts can be expressed about a particular work of art. Within the portrait can be language encoded, a portrait would leave each viewer something different to "say" about itself, varying in stylistic choices and manners.

Visuals preserve language as much as language preserves visuals - perhaps within each painting is a poem unwritten, as much as in each poem there is a painting to be drawn. Paintings within poetry hints at the innate inseparability of visuals and language - such imagination, or the process of decoding across mediums, can be a skill cultivated, gained through exposures on works of both visual arts and literature. Realizing such truth is a gateway to infinite possibilities within the world of art - former distinctions seem arbitrary, lines are blurred between the treatment of each medium, and more life and depth is given to each work of art. There is nothing preventing the reader from reading a poem as a portrait, or rendering the portrait into a poem. The act of reinterpretations and citations becomes an opportunity for endless insights.

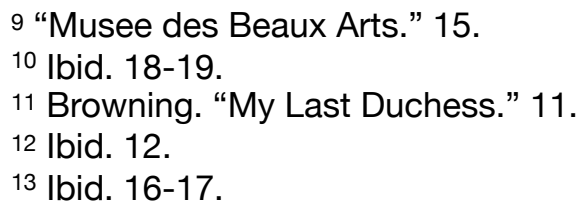




\section{On In C}

Usually each phase in art or the world at large in general seems to be a direct antithesis of what came prior. Minimalism seems to rebuild a tonality from the lack thereof in serialism and aleatoric music, but this tonality seems to be of a different kind: a strangely artificial and repetitive one, mechanically produced and intricately systematized. The tonalities that felt "of nature" or "natural" in previous centuries that had a more religious or humanistic context, in its "connection to the divine", are not to be found: what's left as a reconstruction is possibly culture imitating and reconstructing such lost natural sounds in music, and there is always a certain allure to these minimalist pieces, maybe akin to the same allures of artificial mechanical reproduction, commodity fetishism, and giving into capitalism, etc.

What is minimal in minimalism? What seems to tie Reich, Glass or Riley together seems to be a drive forward, a progression that is relentless - to the point where it drowns out or negates a lot of other aspects within the music. Nothing really resolves in minimalism, nothing varies incredibly from one minute to the next, a moment can be as easily replaceable for another random moment ten minutes in. Change is incredibly subtle: shift in a centre occurs over a longer period of time, almost unnoticeable, an intuitive way of listening to these pieces seems to be losing oneself within the piece. Usually really lengthy, minimalism is hypnotic and invites a loss of consciousness - which might reflect the same hypnotic autodrive that one loses themselves in a working class life.

What In $C$ highlights best can be the role of the individual within a collective. A voice is heard amidst democracy, but under incredibly strict circumstances. There is, seemingly, a freedom of choice - a player can go from one phrase to another when they please, they could skip forwards a bit, but there is not as much creative freedom, or a voice, as it might seem: the individual is necessitated to react to, and have an influence over, other individuals in the performance. Musical motifs as little phrases are parts of a whole that the players work through: they are repeated over and over again, in strange conjunction rhythmically and harmonically with all the other players, before being discarded and never revisited. A player acting out against democratic rules would be the loss of the voice of the collective- which is what matters the most - and consequently the drive forward. The mind-state of the player is recreated in that of the listener - they are letting themselves be taken away and driven forward by the automatism of the unconscious collective, even if the price is the negation of the individual as a listener, or a performer. The audience as a collective attempts to mirror the collective that is the group of performers of the piece.

In $C$, then, is a representation of the processes of mechanical production, almost as an assembly line, the players being the "workers", the score being the blueprint, and Riley as general management. The drama is of the factory, or the average blue-collar job- a dehumanization and a strange role-playing thereof, almost surreal when one, some time into the piece, recollects one's conscious thinking and asks oneself what exactly is happening. Everything seems completely natural, but nothing at all feels that natural: the players as workers lose themselves in the drama of production, as much as the observers as spectators are fascinated and almost recreate the mindset of the workers as they watch the representation of production play out. Culture, in attempting to recreate lost nature, has rebuilt artificial tonality and harmony from total scratch, although making it worse: amidst synthetic unconscious drive is the absolute and complete unrepairability of such original nature, glimpsed in pastiche via polystylism and other similar attempts. Minimalism, as one of those strands of attempts at an impossible restoration, "drives" music and pushes it forwards, in its illusion of restoration makes the whole situation worse, to no avail. 
The piece then becomes more performative and theatrical, music being a utility of social representation, a mirror - possibly diluted - held up to the world at large. The audience comes to a performance of $\operatorname{In} C$ to escape from democratic labour, only to find that such escapism is a representation of democratic labour anyways. It's strangely humorous and brutal - when one regains consciousness and "wakes up" from the hypnotic nature of the piece, perhaps Riley is inviting one to do the same in everyday working class jobs: a strange realization of a surreal autodrive of the collective. A long durationality then only becomes more effective - if In C was ten minutes long it would not have the same effect: the listener wouldn't question it as much, because they weren't given the opportunity to lose themselves amidst the unconscious drive of the music, leading to a conscious reflection of the automatism of the collective in the performance, consequently leading to a conscious reflection of one's autodrive within everyday life. " $\mathrm{C}$ " is the tonal centre, the agreement between the workers and the listeners that Riley might want both parties to escape out of: to realize what is happening beyond such centre of agreement, to view the piece from without.

Does music itself become of less pertinence, then, if what is at hand is social realism? Does the language or grammar of music become less important, and does it ever become less essential? The right question here could actually be: is music ever not such realism? Can it ever not reflect the world at large? Can it fully separate itself from the world? Didn't absolute music in such attempts end up saying things about the state of the world that made itself possible in the first place?

No matter how hard it tries, a work of art seems literally incapable of not being relational to the state of reality at large, to be affected by and have an effect on reality - music can never not be essential, as it is a necessity of such reflection of the world. Music as mere utility of dramatic representation, is still music in essence, although it seems as though it has strayed away from its original beauty and reasons of being. However, amidst innately within those earlier Christian or humanistic works is the very same social realism, decoded in hindsight via theological or cultural studies of the context of those specific times. There is not really a limitation that is innate within works of art except those that are self-imposed: $\ln C$ is music, theatre, performative, reflective, self-destructive, all of the above and none of the above at the same time.

Essence of music seems to have become more representational around the time of minimalism, possibly because the essence of an individual, or the world at large, also became more representational. The world after this period of time, into the 21 st century, seems to stray into complete simulacra - and music doesn't ever seem to fail to reflect such a state of the world by becoming equally as absurd as a creative reaction. Minimalism as a whole, and $\operatorname{In} C$ within it seems to be an apt bridge: the automatic "drive forwards" possibly being a selfdestruction of the negation of the representation of the individual, a withdrawal into complete simulation. An ability to create or receive such a reaction from a piece as a composer or a listener is intuitive, or a skill that is cultivated: "gauging" out the realities that lie underneath the piece takes work, but the basic truth generally seems to be that one can only "see" :) as much as they know. 


\section{On Disney}

Disney films are interesting because they are simultaneously the encouragement, and the exploitation of children's moral values - the whole company holding a monopoly over franchised narratives that actually do go on to sell well outside of the film itself, as merchandise, in theme parks, and so on. To even try to begin to imagine the bureaucratic operations behind the whole scheme would take a lot of time and effort, the narrative of the film is relatively only a minuscule part of the whole franchise, but also perhaps the most important, as it is technically antecedent to everything else that comes after. There is a dependency on how well the narrative of the film does, how well they are imposed onto imaginations of young children for the company itself to keep running.

Animation, then, becomes a utility. It seems to be an apt medium, as it reflects quite well the modern world's "simulations" a la Baudrillard. Looking at Disney animations aesthetically as of recent is a sort of dumbed down hyperrealism - facial features are exaggerated to the point where it has no semblance of reality, which is probably be helpful because its more applicable to a larger quantity of people, as features are generalized to the lowest common denominator. The colour scheme is heavily saturated and contrasted, the closest thing in art history that precedes and resembles Disney seems to be surrealism (Dali, Magritte, etc.). Thematically both surrealism and Disney seems bright and strangely comforting, but underlying both is always the sense that something has gone deeply wrong for the world to need such an artificial sense of comfort in the first place. As surrealism "worked" in the 1920s, Disney seems to capture the imagination of the 21 st century.

Along with the film are songs as commodities, probably equally as intricately engineered and discussed over, as the pop appeal and the reach of the songs drive the revenue of the film and vice versa. Disney songs are near-perfect commodities - the structure is incredibly intricate and compact, there is no fluff or any sort of excess in how it's written or produced. Although it doesn't top charts per se, they are, at its peak, often as known as chart hits - possibly because of the naivety of its target demographic of the grander bureaucratic schemes behind the commodity process. Interlacing the songs through the narrative has become a fairly common trope, and films like $L a L a$ Land may as well be a live-action Disney film: the form and narrative structure, and consequently its marketing and distribution schemes - of the songs along with the film - is too similar to that of to not go unnoticed.

Most narratives of Disney in-itself are only representational because an identifiable source can less easily be found, because such cultural narratives aren't something that is extensively researched or catalogued. Remnants and fragments of these mythologies are pieced together, by Disney, into a coherent structure, that is valued, ultimately, by its marketability. One can say, in the modern world, finance is that which determines the structure of these religious narratives, not that it is faithful to its respective origins. "Exotic" narratives, then, are more pliable and malleable to adaptations within the dominant market, because its own origins are diluted and difficult to trace due to the lack of proper research - or the lack of popularization thereof. Polynesia, Scandinavia, and other regions such as Madagascar, being the lesser dominant groups of narratives geographically and culturally, are more pliable, then, to such appropriation to fit necessary demands.

The choice of a religious cultural narrative to be commodified, then, amongst many, is necessitated to be one that's a lot less relevant and controversial in the grander scheme of things internationally. Had Disney used religions that were more relevant, perhaps Christianity or Islam for example, it would not go down well: much political connotations that are too pragmatic to be ignored would seep right into the film's commodified narrative, which can actually be dangerous, considering how much influence Disney has over the film industry. By 
choosing, purposely, a minor narrative in the grander cultural scheme of things, such exotic connotations and genuine mythological beliefs of a group of people can be commodified to be sold, but without the political consequences that might be latched on had it been more relevant and prevalent.

The questions of morality, then, are what happens when the representation of the religious mythological narrative takes over the importance of the original narrative itself. Is Disney justified, in the name of commercial gains, and children's morale boost, right to overwrite genuine culture that means a lot to its native people? Furthermore, to what degree does a religious narrative already overwrite an existing culture? To what degree does it pervade over the culture? Can a religious narrative ever not encourage and/or exploit people? What is the innate connection that people feel from religion? Is a Disney movie, in a sense, religion itself? Are the lines drawn between such distinctions only arbitrary? Is religion innately immoral?

Is religion ever not, however, such appropriation to fit the demands of the time? Are these original sources that one seeks for equally as exploitative as a commodified narrative? To what extent is The Bible like a Disney film? Didn't it have to fit the demands of the narratives of the time, and comply with the very same structural demands of what things would have been like back then? Isn't The Bible exploiting what people want to believe?

The value of something "original" may be, merely, the idea of an antique hindsight, the separation over a longer period of time that might endow its value. Lost over time, then, is the idea of the same structures that were in place - pragmatic, economic, geographical, etc. and all that seems "divine" is the material in-itself, that seems to transcend the necessities of the world around it, holding the value to its own material, justifying itself. The Bible seems "sacred" in-itself, because it seems to have no relation to the world at large at the time. People who believe in the text are not necessitated to look to the pragmatic structures, but merely the narrative on its own that somehow seems to justify its own existence. Such structures are lost over time, because the longer the interval between the present moment and a point in time in hindsight, the more difficult it becomes for the person to place themselves in the shoes of such an antique past.

Disney attempts the same thing, but without the time interval necessary, via a representational narrative. If the narrative recreated in Frozen is forcefully severed from its Scandinavian origins, it's almost as if the pragmatic world isn't necessary, and it's almost as if the narrative justifies itself, having the seemingness of a value in-itself. Disney is a world seemingly without these pragmatic structures, for the dreams of children: there seems to be no finance, no commodities, no representation, no form, just a good story for the sake of itself; one that justifies itself. It sparks the imaginations of viewers that makes one feel as if they were a child, having forgotten about that which is necessary to spark such imaginations.

Fundamentally, what's the appeal of Disney? How do they do so well? Perhaps they give the viewers what they want - stories that sever itself from the outside world, for people's imaginations to get lost within, without the pragmatic realities of the outside world. 


\section{do the right thing}

It could be ideal to not have such a distinction between the acts of "recording" and "constructing" the world-- they could be one in the same act. Film is a medium for such acts to occur, and the freedom of the filmmaker in their choice of styling, form, and content is seemingly infinite. Both "Man With a Movie Camera" and "Singing in the Rain" are films about the possibilities of films-- separated by a timespan of about two decades, and cultural contexts across the Atlantic ocean. Vertov presents a construction of a particular mechanism of a social and political world: the architectures of cityscapes and the mechanics of the production line are as much of characters within the film as actual people. It becomes unclear whether the work is being done by mechanics on people or people on mechanics, and such analogies are present in the film: the film features mechanical labour of the film itself, as viewers are presented with literally what made the film possible. Kelly, twenty years later, does something similar but with social worlds: he discusses questions of to what extent such simulacra of the movie industries actually "happen". An industry has grown on the basis of film and entertainment, and the audience has trouble telling apart the intricate bureaucracies of the industry from reality per se, as there is no sensible line to draw from what happens "behind the curtains" to what happens in front of it. The film records the making of a film and its sociological effects: the deceits of the industry reaching the public and private lives of the actors that run it. Both these films, then, present a worldview, recorded and constructed based on the fictional realities of the world, that run a direct feedback loop of pragmatic effects on audiences and social realities. Vertov can reflect and shine a light on the growing mechanization of labour, as much as Kelly can on the consequences of entertainment. By rendering the world within the medium of film, the world is rendered through film. The world is recorded in its constructions, then constructed based on its recordings.

Like many art-objects, or life in general, movies are what the viewer makes of it, and its richness can be preserved by not categorizing it into a certain form, but maintaining a versatile approach from the viewer's point of view. Nothing hinders the viewer from rendering a film simultaneously as art, entertainment, and a commodity. A critical analysis can be done alongside an emotional viewing-- an overly analytic attitude could ruin the film as much as mindless viewing. "Man With a Movie Camera", for those with a historical connection to the time and place, could stir up emotions and could be remembered as an archival documentary. "Singin' in the Rain", for music enthusiasts, could be merely ear-candy and remembered for its bangers. Once one realizes the limitless nature of the "viewer's experience", questions about critical analysis of art itself can be raised: is it a process akin to a scientific experiment, or can it be less rigorous and disciplined? Is the academic's viewing of a film any more or less meaningful than the casual viewer? Exposure to film theory doesn't have to mean entering another world whilst leaving behind another, it could be merely the cultivation of ability for a different type of pleasure: one of careful and higher-level thinking. Even within the world of theories, a lack of strict disciplinary boundaries can be found: there is nothing stopping the academic viewer from viewing the film according to literary theories, philosophical theories, etc. In the context of the world at large, a film is inevitably rendered a commodity, and economic theories of the can be applied to find out why a certain film "did well" in a specific time and place-- one can render the market an object of critical analysis, as much as the film. The question then, of "how should we think about movies?", then, is best left unanswered, in the interests of freedom. This doesn't mean, however, that such academic work is futile-- merely that versatility can be valued more within academia.

The question itself of "Doing the right thing" in Spike Lee's "Do the Right Thing" might be the answer-- often the right thing to do is to think about what the right thing to do would be, and to not be hindered by what others deem what the right thing is. In a complicated microcosm of race relationships, relationships are hindered by race, and race is hindered by relationships. 
Questions of morality become as complicated as the relationships between relationships and races within the microcosm. Violence can seem humanitarian, and what is humanitarian and in the best interest can seem like violence. Ethics and morality, then, becomes complicated within a context of imperfect social contingencies-- what is subjectively the right thing doesn't mean that it is objectively the right thing.

What, then, can be objectively the right thing? One possible answer can be the choice against ignorance: ignorance breeds more ignorance, and seems contrary to what is ideal and humane-- mutual understanding. America's histories of the lack of mutual understanding, and failing to see the human beneath their race has deeply scarred world history in general. Though such practical practices of segregation and enslavement have slowly died out, the hurts and stained legacies have not, the divide between could still to this day seem more apparent to some more than others. Sal wouldn't even think of putting African-American people on the wall-the picture of America that he imagines is far from Mookie's or Buggin' Out. Perhaps understandably, neither could even imagine the other's America-- Buggin' Out can't imagine an America without the contributions of African-Americans, Sal can't imagine an America with them. The emotional divisions segregate each other into different ideal worlds, where they would prefer the lack of the other in exchange for easy conformity.

In reality, the truths of mandatory coexistence itself might override ideal worlds: the Pizzeria is "owned" by Sal, but frequented by, the black people in the community-- although the Wall of Fame, or the ideal world lacks African-Americans, the pragmatic world necessitates them. Mookie, in working under the business, is the running of the business-- this is analogous to the way in which the black community, in working for the social microcosm, has become the microcosm. What is seen as the structure of America-- the workings and labour of white people-- is far from the actual America, which necessitated the labours of immigrants of different races. Ignorance of history and pragmatic reality for a comfortable ideal world, then, is an illusion forced upon oneself for Sal: one could argue that this is more an act of violence than the destruction of the Pizzeria. Ignorance, however, breeds ignorance: the destruction of the Pizzeria confirms the very existence of the symbolic ideal world, and in essence fosters division. The film can be a reflection of the reasons behind the irreconcilability of modern race relations in America: the white American's ignorance of the pragmatic world and continuous retreat into the ideal world of perfection merely breeds other races' want to create division, perhaps understandably.

The film is a reflection of such complexities, and currently unresolved tensions. Merely highlighting the tensions, however, could possibly be the first steps towards understanding. "Doing the right thing", then, could be restated as "accounting for the multiplicity of worldviews, and acting pragmatically in the best interests to each and every single one of them, even if one realizes the complexities of such action and the fact that it is the more difficult thing to do". Simply it could be stated as "putting the human being before their race". 


\section{vera chytilova}

Czechoslovakia during the cold war was in a general state of distress-- the complexities of the state can be in an overgeneralization be summarized as thus: there was an implicit sense of upper class elites that were benefiting from privatizations of resources, guised under a communist dogma of equality. Czech New Wave, or the filmmakers grouped together active around the 60s and the 70s, inevitably, had to be reactionary to such social injustices. Censorship was prevalent from the government. When the style of socialist realism that the government partially enforced during the 50s ceased to be of interest to the filmmakers, they turned to experimenting, with both the form and content of their films, letting in influence from the rest of Europe. Social commentaries were disguised with allusions and allegories to resist interventions from the governments.

Věra Chytilová was born in 1929, and worked as a model before being admitted into film school in Prague. She graduated in 1962 and her career reached its peak after her graduation in the $60 \mathrm{~s}$ and the 70s, and she continued making films well into the 21 st century before her death in 2011. Both artistically and politically, her life can be seen as an active one: when the government indirectly stalled Chytilova from her work after her most controversial release of Daisies in 1966, she wrote a direct open letter to the then president of Czechoslovakia Gustav Husak, entitled "I Want to Work". Her tendencies for direct social involvement, not only within her films with anti-state commentaries, but also in her political fight against government censorship, can be traced as a recurring theme in her life.

Trying to describe Chytilova's style of filmmaking in a neat manner would inevitably be a stretch, as both the stylistic choices and the themes of discussion varied heavily spanning her career. What did remain constant seems to be a tendency for experimenting, and a heavy disregard for conventionalities-- conventionalities of film both within the time and place of her life, but also conventionalities of film as a medium in general. As a result, her films are often hectic, ridiculous, and confusing-- and in different manners. Her general style seems to be a lack thereof, her work changed drastically not only from film to film, but within a film as well.

Chytilova's 1961 debut work Ceiling was a relatively tame film, made after her graduation from film school. It is a realist film that traces a model through her lifestyle, raising questions about the profession itself, and moreover the status of women in her time and place. Already here are certain tendencies in place that come into fruition in her later works, such as her particular way of framing a narrative, use of surreal music, and so on. Her follow-up films treated similar realist subjects, the 1962 A Bagful of Fleas follows a female textile factory worker, the 1963 Something Different follows an olympic gymnast. This early phase, however, was disciplined and conventional, within the context of her entire filmography.

The 1966 Daisies stirred a lot of controversy-- not just from audiences, but also from the government, and is the film that established Chytilova's place in the film world of Czechoslovakia and surrounding regions. The film itself is better watched and experienced than explained, but in a crude generalization, it follows two nihilistic young girls that cause havoc in various happenings, they play with food, and men, and men eating food, and generally misbehave themselves in public. The narrative feels surreal and incoherent, and is furthered by the editing techniques, often colour schemes change from scene to scene, found footage is spliced without any explanation, and so on. Her films from around this era are the most celebrated and watched, as this was the peak of her controversy-- the 1970 Fruit of Paradise was even more surreal, and the 1976 The Apple Game followed a similar manner of storytelling.

Chytilova's films were stalled around this point in time by the intervention of the government. She wrote two separate letters to the president of Czechoslovakia explaining her and her colleague's situations-- artists in general not having the freedom to work, female artists being more 
disregarded, a general plea for help. It was also around this time-- the $80 \mathrm{~s}$ and $90 \mathrm{~s}--$ that a gradual transition towards a more free market occurred. Along with it came more freedom from the industry, but ironically Chytilova took a more realist approach from this point in time, still keeping her surreal editing techniques and characteristics from her peak. Prague: The Restless Heart of Europe, from 1984, is a documentary survey of the city's cultural origins. Panelstory from 1981 follows fights of tenants hoping to move into the same industrial neighbourhoods. There was less symbolic material in her later work, but realist stories were edited and dealt in the same manner that the surreal stories were dealt with.

Understanding Chytilova's work can perhaps be an insight into similar movements in arts, such as dadaism or surrealism, that radically had a passion for disorder and disregard for former conventions of art: is such direction of passion justifiable and worthwhile? Why the fuss about conventions, when they can be useful when adhered to? Is it immoral to disregard what's come before in art, what previous generations have built up? What can Chytilova's legacy say about art in general?

Chytilova's films seem to be better food for thought than an ordinary film. The connections between the world of her film and the real world are existent, but encoded in a way that the viewer has to look for it rather than it being in plain sight. Not only does it challenges the viewer's primary instincts, but also their conventions of what is possible within the context of a narrative, with the film as medium itself, in turn forcing it forwards, rather than merely reproducing what is the norm.

Progress, or adaptation seems to be better than decadence, or mere adherence in this case. Often the current state of film as a medium would not do for directors like Chytilova. Perhaps the way Chytilova viewed the film as a medium is analogous to her political and social worldview-violence that she does to the rules of cinema can be analogous to violence to the contingence of such social structures. Still, what is the nature of such violence?

Ultimately, Chytilova's non-adherence can be explained as an exposure of sorts, of the contingency in both the rules of cinema and social orders. There is no real reason that film is made in a certain way, and artists can feel constrained by such rules. Deliberately choosing not to conform to such rules in film exposes the contingency of rules as a product of a certain time and place and in no way necessary, and such process can be a reflection of the very same contingency that Chytilova fought against in the political and social world, namely the soviet control over the eastern bloc during her lifetime. Although her times have passed and culture has moved on, the legacies of Chytilova itself keeps resistant flames alive.

\section{Further reading}

Chytilova, Vera. "I Want to Work." Retrieved from https://journals.sagepub.com/doi/pdf/ $\underline{10.1080 / 03064227608532516}$ 


\section{daisies scene analysis}

Věra Chytilová's 1966 film Daisies follows two young women causing havoc in public, playing with food, and staging general mischief in various happenings. The film stirred controversy, understandably so, because the stances of the characters, and consequently the director, seems at first glance to be diluted and left unclear: Daisies has been read as an anticommunist film, a feminist film, an anarchic film, and got Chytilova banned from her work by the government. Attempts to make sense of it only causes more questions than answers. The second sequence is an introduction to the biggest question(s) of the film: the main characters, Marie I and II. An insight into the peculiarities of the two main characters is an insight into the deeper threads that underlie the film-- the second sequence is important to the whole of the film in that it is an establishment, and an understanding of seemingly impenetrable characters can be a leeway to further clarity of the stances of the film.

The second sequence follows the opening sequence: close-up shots of working gears, juxtaposed with aerial views of landscapes bombed. Heavy industrialization and its consequences is set as an undertone before the second sequence. The sequence in question, is surprisingly straightforward: two girls in bikinis sit leaning against a wooden wall on a carpet, facing the camera in a medium-long shot, with their full bodies framed. They awake from their respective naps, one picks her nose, the other blows a trumpet. A door creak is edited in to mimic every gesture that they perform. They engage in a puzzling dialogue: "I can't even do this."-- "We can't do anything."

There is a sudden cut to a wall of a building falling down, followed by the camera with a tilt downwards. The shot ends as abruptly as it started. Marie II has put on a flower crown, and declares herself a virgin. Marie I is unphased. They declare that everything is going bad in the world, and this moves both from apathy into elation. They sit facing one another, finishing each other's sentence: "If everything is going bad, so we're going... as bad... as... well". The only movement of the camera within this particular shot, a tilt upwards, is accompanied with a snare roll, building tension. Marie II finally asks, "does it matter?", to which Marie I replies, "it doesn't matter", slapping Marie Il's face into the next scene, which begins with her falling backwards from this former sequence into a field of grass.

It can be helpful to discern what a sequence is attempting to do by acknowledging what it isn't doing: there is barely any movement of the camera. It is rendered black-and-white, compared to the rest of the film, which does have colour. The absence of complexity in stylistic techniques can redirect the focus into the complexities of the content: namely the dialogues, gestures, and expressions of the characters. The characters framed here are eccentric to say the least: they initially seem apathetic to the point of inhumanity. Their gestures are performative, meant for an audience, a symbolic presence is evoked for each and every gesture, in a way that is absent in reality. The non-diegetic sound of door creaks that are mimicking every movement of the characters imply a mechanization and objectification of the self, a rendering that dehumanizes both the characters. The door creaks are almost in conversation with their actual diegetic conversation, which if dug into are equally as confusing: it is reminiscent of a Beckett play, where a lack of continuity and context becomes prevalent within dialogue. The viewer can see that they are dealing with irrational characters, rendered by the world as objects, similar to the way that the viewer's gaze renders the actors as objects.

A notable shift in the mood can be seen in the characters when they become aware of an underlying fatalism that comes from such mechanization and objectification, it liberates them in a certain way: everything is morally corrupt, which is a justification that they can be morally corrupt with it. They can render the world as their objects as much as it renders them as objects. The director also seems to find liberation in corrupting the form of this sequence: the lack of an 
apparent meaning in narrative can be best displayed by the dialectic of the two juxtaposed shots of the girls talking with the destruction of a building. The two shots within the same sequence is not an easy synthesis-- every attempt at a coherent synthesis seems to be a reach, and is left undetermined and unresolved. The sequence seems to suggest, along with the characters, that in such irrationality is a sort of liberation, deliberate against interpretations and easy answers.

The surrealistic world that the sequence and the film operates under is always a ridiculous one, in that it doesn't seem to resemble reality in a rational manner, in narrative, content or form. It always follows symbolic presences that are diluted within unconsciousness: the flower crown can mean purity or lack thereof, a trumpet can allude to the realities of war, but it's never concise in a way that many would hope. A repeated viewing of the sequence is like assembling a puzzle: it seems more and more deliberate and intentional, clarity is gained, not given. The sequence in discussion renders the characters, and consequently the film itself as both a reflection and a critique of the joys of destruction. Marie I and II are rendered by the political and social corruptions of the state, then "become" the corruption, reveling in the joys that can be found in destruction of the self, the idealized state. Analogous to the destruction of conventions, it is both at the same time a celebration and a critique of the forces of destruction in a medium of film and in the self, making the viewer aware of the duality of the dangers and the joys of becoming. 


\section{the matrix}

It can be argued that the action in The Matrix might be less about actual physical fighting between characters, but between the discourse of religion with the cliches of a traditional "action-hero" film. The uneasy balance between the two stems from what seems like an absence of one in the other: there seems to be no deep character arcs, questions of salvation and sacrifice, eschatological troubles that are found in religious narratives in action films, as little as there are proper romantic tensions of the "hero" in religious narratives. Upon closer inspection, however, one is not nearly without the other: Neo can be the messiah, Cypher "betrays" the crew, there are narratives of good against evil, truths and illusions, the morality of choice between proper knowledge and ignorance.

In the juxtaposition between two seemingly unrelated forms of literary styles, separated by millenia and mediums, and apparent sacredness, religious questions are definitely amidst the entertainment values of The Matrix, perhaps in a more diluted and contrived manner.

Consequently, there is nothing stopping readers of formerly sacred texts like The Bible to read it as if they were watching The Matrix-- finding the same entertainment values and shock factors, possibly outdated literary effects that one can laugh at: the possibilities of analysis and "reading" and "seeing" become near-infinite as such distinctions wear out.

The unease of the juxtaposition might be the innate inseparability of religion and film. Some bits of The Matrix are ridiculously corny, albeit apparently moving-- it had financial success and multiple sequels-- which means that something resonates that stands the test of time. The messainic figure is no longer divine, but it could just as easily be a guy with a computer, falling down "a rabbit hole" of levels of image-laden unrealities to save the world from its own simulacrum, an expulsion into the desert of just generally being and feeling out of touch. There is no garden, there is no flood, just levels of delusions that a catalytic team of disciples must save themselves and others from, within a character arc of a predestined self-sacrifice.

There is, then, something that doesn't change between two millennia: a necessity of structures of belief on a collective of workers, and ideals of-- however delusional-- future utopias and lost arcadias. The world needs to be saved from itself, something fundamental has gone wrong. Hence the necessity of the flood in The Bible, or the general unease of a green colour scheme that just never goes away in The Matrix, which really makes sense if its pointing to the lost colours of the garden, and the unlocatability thereof in the modern world: a semblance of Eden might be the binary codings and computer structures, an internal structure that keeps the image-world running. There is no nature, there is barely any culture, but merely automated authority that feels really arbitrary and silly-- it may as well not be.

Complaints here, then, might just be a generic lack of actual literary depths: the name "Trinity" just feels like it was there just for it to be there-- no deep theological roots or concerns regarding the Christian trinity were discussed. Complaints of dumbing down "Morpheus" from antique mythologies could also occur-- merely adapted, emptied of its former character values. This really can't not be forgiven-- the generic western irony seems to be a devaluing of myths that once seemed extremely serious, a certain joy of bringing down all these formerly unreachable figures and figurines of polytheistic and monotheistic trends and playing such roles as merely human and discardable characters within culture. Neo just feels as generic as possible, yet he is the one: he learns eastern tactics, works within and out of the system, eventually becoming "one of 'them"'.

It's just more fun to see the religious aspects of film, concurrently with filmic aspects of religion. Deeming The Matrix as purely religious or purely entertainment can be an approach as outdated as its special effects. 


\section{the platform}

When faced with grotesque notions of human nature, possibly incredibly brutal ones within literary narratives, it can always be helpful to remember that such perspectives might be contingent, and not always necessary. "Vertical arrangements of people" is always fascinating-possibly stemming back to Tower of Babel-- but such a notion, ironically, seems to be increasingly more relevant in today's society: people are rearranged accordingly to class hierarchies on which their lives are dependent on, there is a lot of contempt and disregard from those above to those below, which might be an apt for today's time.

It can be helpful to understand this film in the context of J. G. Ballard's "High-Rise", or its consequent film adaptation as a complementary narrative-- the hierarchies, however, in "High-Rise" is built from the ground up, as opposed to "The Platform", where it goes below the ground. The two in conjunction are strangely reminiscent of Dante's Divine Comedy, which was possibly the first construction of hell and heaven into strangely pragmatic sections, the "nine circles of hell" possibly being an apt narrative mirror for looking at the arrangement of "The Platform". The division of people into spiritual classes of value are inevitably merely mirrors of pragmatic social hierarchies.

The architectural spaces above and beneath reality, then, are a representative simulation of what happens on surface reality. The spatial context is no longer above ground, reaching towards heaven, but below, aiming to get to the centre of the earth-- where people in claustrophobic starvation cannot see the "light of day". Each character within the narrative is not an original, but a representation, or a common denominator-- it is important that Miharu "represents" her race, gender and class division in the real world, and of less importance is an innateness of being, which might be forgone for an ease of story-telling, perhaps understandably. A relation to reality becomes one of representation within a simulation.

The context of the representative simulation, then, rids the innate being of the characters by rendering them what they are within the self-management centre: characters that exist primarily to serve the mere notion of verticality. They exist only and primarily to keep the whole of the system of representative simulation running, and are driven mad by becoming selfaware of their inescapable situation. Perhaps their original selves are lost to the context of the simulation-- they can no longer imagine themselves on the surface of the world as a proper person, they don't see themselves as properly existing outside of distribution of wealth via random class division as representation, perhaps a mere show for the "administrators".

The only illusion of free will here is that of food-- people of the upper class interact with those of the lower class, via the choices of the quantity and quality of the food that they provide them with. Everyone in the centre is bound to it as a dependency, a necessity for survival, but it is also what drives people towards inhumanity: a difference in quality of food is literally the representation of their position in the centre, the locality of their representation. It might be the root cause of such inhumanity, the only notion that is "of nature" in the context of the narrative, ironically, serves and fuels unnatural inhumane desires.

It's easy to forget the inhumanity present and portrayed within the film is the result of a specific context of deprivation and class division-- a contingent situation of a specific time and place-- which in no way is a necessary innate notion. There is inhumanity, but only as a result of a specific arrangement, perhaps designed to drive out such feelings, which, the director seems to be arguing, is maybe not too different from the arrangements of the world at large contemporarily. Amidst hell as a place on earth, the girl as a message to administration is a possibility of naivety, an original semblance of nature, akin to the panna cotta, an incentive for some kind of rearrangement that might better serve the world at large. 


\section{night of the living dead}

The essence of zombies seems to be that their whole being seems to be a representation of death: they are mindless and stripped of their consciousness and individualities, however united their mindlessness is a collective as an entity-- that almost becomes conscious in their willed attempts and desires to spread the infectious "being as representation of death" onto those that still possess a semblance of individuality. The "undead" is defined negatively-- the phrase itself seems to have in itself a connotation of inevitability-- the fated destiny of all beings to eventually succumb or be taken over by the "mob mentality", perhaps a metaphor as social critique of mindless indulgences within the modern world in general.

Zombies are probably prevalent because they serve as such an apt narrative for the time and place that the modern world is: the narrative of good versus evil is no longer religious or heavenly, but extremely pragmatic to the point of brutal necessity and survival-- mindlessness is a consistent threat that the house's inhabitants as social microcosm, one that they need to consistently be anxious and defend themselves against, even when one by one they are possessed until there are almost none. Perhaps people feel that being a proper individual is something to be on guard about consistently-- the mere idea of giving into the mob mentality might be a source of temporary comfort, a reassurance of sorts amidst constant threats of loss of individuality that one might feel in the modern world.

The question of morality in killing zombies can be a question of their status of consciousness: whether it is fully possible to negate oneself into a collective-- if the belief of self-annihilation could actually make for it being true. Chemical accidents, not divine preconditioning, resurrected the dead, not as salvation, but into an inanimate status. There was no choice in the very origin of these creatures: it seems like it was a historical accident-explosion of a space probe, completely uncalled for in its contingencies. Zombification then probably implies a genetic mutation of sorts, a biological malfunctioning via synthetic penetrations toxic enough to turn such humane consciousness off-- where free will of "giving in" becomes less a conscious choice, but more a happenstance. Nobody asked to be a being that negates itself as representation of death-- it happened onto them perchance.

The imperative to spread the representation of death is complicated by its genealogy leading to a chemical accident at first glance-- but it can always be traced back to an act of human will: attempts at space colonization, the want to seize control of nature having gone wrong. The biological theories, attempts at trying to draw a completely arbitrary line between the consciousness and the lack thereof sort of defeats the purpose: the debate always serves itself. Such iffy origins might be the horror of the concept of zombies-- they are, essentially, birthed by humankind in their brutal Frankenstein attempts against natural and divine creation, under the guise of historical happenstance and accidents. We essentially brought the representation of death as being onto ourselves.

It doesn't really matter if it's right to kill a zombie. Such unanswerable questions seem to be always brought upon ourselves in theoretical guise, where the bigger problem of even having such a question seems to imply the fact that something has already gone irreversibly wrong in the grand scheme of things. The fatalism underlying the film seems to be the fact that it doesn't really matter if one becomes a living representation of death, or just dies-- death comes to us all, now often even during life as a constant threat, due to our own irreversible actions in the grand scheme of things. 


\section{silence}

For Father Rodrigues, mere faith is blind ignorance, and consequently his selflessness is egotism in disguise. A father mimics Christ in mass and life, reciting verbatim from the bible, as if he is, in fact, the Word made flesh. Strange performative gestures in Christianity such as baptism, confessions, eucharist, all refer back to Jesus' doings back in his time, as if exact mimicry enables one to fully become a historical character, ridding oneself as an investment.

Such legacies of missionaries through the histories of the Church, then, are less about the legacies of the individuals that are in mission, forcing syncretism upon other nations without apt historical roots, in attempts to translate that which takes time and effort, not force, to properly translate. The individuals merely "serve" the legacies and iconographies of Jesus Christ and his tales, which in turn were bureaucratic state tools for European nations-- with underlying ideological beliefs: representational orientalism, possibilities of colonial trade exploitation, as mere political utility for potential subjugations in the long run.

A group of eastern people that believe in Western utopias suffer from the actions of those that they deem superior. For the less fortunate, the West itself is the messiah-- from their financial situations or general quality of life. For the Japanese aristocracy, then, such attempts at subjugation are annoying disruptions to a functioning system. The more fortunate in this case have the adequate quality of life enough to see through the dilutions-- akin to the beginning shot of the film-- of such cultural egotisms masked by false narratives of justice and righteousness.

What grows throughout the film is the level of delusion of Father Rodrigues. Perhaps aware of his own narcissism subconsciously, Eastern suffering only supports his former egotism: Rodrigues as Jesus can't give up, basically, his own reflection in the lake. Such hysteria after facing himself might be the most truthful part of his character: he can't really see through anything but his personality that he has created for himself-- there is nothing else to hold onto. The dichotomy between Father Ferreria and Rodrigues-- the old that has already resigned themselves and can their own futilities in the prospects of the young-- is a familiar character dichotomy in literary history.

Father Ferreira has learnt to see both sides of the situation, and came out the other side as a pessimist. Perhaps this is not inevitably so, but more an admittance of character weakness: ideally it should feel more liberating-- such differences should be one to celebrate, not to mourn over. Eastern culture can go on to effectively support and help one better understand Western histories and its contingencies, and vice versa: although the former delusions of a monothestic religion and culture of the West are long lost, such loss is merely a leeway for comparative cultural studies, which is more effective than pigeonholing oneself.

Silence is, then, a lack of a divine intervention, because what was happening on both sides weren't exactly moral from the get go. An external force doesn't listen, respond, or communicate effectively, probably because people are being dumb. The film seems to say that such external absence is an integral part of internal presence: the essence of the self, the voice of genuine self-confirmation that feels pleasant, and never leaves amidst all delusions that one creates for oneself. The voice of the fumie may just be Rodrigues' true self admitting to himself that the essence could never be completely overshadowed by its own appearances even if it wanted to. The silence is the voice. 


\section{notes on photography 1}

Photography, Benjamin says, having been driven out of art, is a very "dangerous field"-as it is easy for photography to slip into purely functional states, serving merely "physiognomic, political, and scientific" interests. In such a case, there is no longer any semblance of artistic merit, but it only becomes about "salability than of any knowledge", the "advertisement". It fails to reveal anything about reality itself, as it becomes only a pure reflection. As a reaction to this state, photography must be "constructed" on top of reality, as other mediums of art do: Benjamin mentions both the Russian filmmakers, and the Surrealists for this sense of experimentation that photography was inspired by-- not to merely reflect reality, but to have something "be built up, something artificial, posed" on top of it. Antione Wiertz, cited in this reading, believed that the camera as a machine "will be the brush, the palette, the colors, the craft, the experience... the very essence of painting [when it] has grown to its full stature". Baudelaire, in a reaction to this reaction, mentions that photography must "Revert to its proper duty... [serving] as the handmaiden of science and the arts" because "if photography is permitted to supplement some of art's functions, they will forthwith be usurped and corrupted by it". Baudelaire believes, that constructing a reality as photography, being inspired by other mediums in art, is actually a regressive reaction because it ruins what he believes to be the essence of photography: that which can capture reality in its accuracy. Baudelaire wanted to negate the reaction, in hopes to bring back the original functional means, having rid the endowed artistic merit as the reaction. Benjamin compares Wiertz and Baudelaire, the thesis and the antithesis, the reaction and the reaction to the reaction, to provide his own synthesis: photography neither endows extra meaning, or completely rids meaning into pure functionality, but the efficiency of the technology itself, "the camera... getting smaller and smaller, ever readier to capture fleeting and secret images", is able to pull out the literary meanings of the conditions of life which are inherent initself, "every square inch of our cities a crime scene... every passer-by a culprit". For Benjamin, the inscription is the most important part of the photograph-- that which isn't endowed on top, or completely devoid of meaning, but that which, via the photography, leaves a mark on reality by capturing meaning that was already there anyways in reality. It would be a mistake, to endow extra meaning onto reality, because it strays the viewer and the photographer further and further away from reality, as much as it would be a mistake, to completely leave photography devoid of meaning, because essentially, this is an impossible act from the get go-- as innate meaning within the conditions of life is not something that can be completely detached and made devoid of via photography. Being a literate viewer, then, would be being able to note the "inscription" of the photograph-- the manner in which the photographer chose to drive out the meanings that were already inherent in the "square [inches] of the cities" and the "passer-bys". Benjamin, in his synthesis, almost drives the entire historical situation back to square one-- the first photographic portraits that didn't need such theories to justify its existence: photography merely was in its origins and conceptions, the ability of a hindsight itself, the "interval of ninety years that separate us from the age of the daguerreotype" allows theorists to endow meaning onto the situation of the medium of photography, almost like the photographer, who makes his own inscriptions on reality. Being a literate reader of the whole dialectic that Benjamin hypothesizes, almost could be like trying to decipher Benjamin's "inscriptions" on the historical dialectic itself: Benjamin can't put on extra meaning to that which has happened, he can't completely strip history of all meaning-- he is required to drive out the meanings that are already present in the historical realities of photography, making his own "inscriptions", his own markings onto the situation, using language as utility for history. To what degree, then, does Benjamin succeed in his acts? Does it drive the historical situation forwards, does it leave it where it is, or is it actually regressive or counterintuitive to the whole situation? Benjamin mark the first photographs as "beautiful and unapproachable"-- the firstmost portraits are unapproachable in its beauty, whilst being beautiful in its unapproachability, because its origins were that which merely were in its conception: not a lot of theory or explanation was necessary, as having been birthed, such naivety was the freedom to do whatever, not knowing what it will have become in hindsight. The lack of self-consciousness that used to be and is no longer in photography is what Benjamin 
deems lost: inevitably, photography is contextualized, reimagined, theorized upon, and "inscribed" onto as others wish. A perpetual flux is necessary in photography, because the lack of self-consciousness, a return to the origins, is not something that is possible in the conditions of photography. Benjamin's inscriptions onto photography itself merely is, and it is up to the literate readers that come across his essay, a matter of opinion for them, to decipher if he had been constructive or destructive-- a hindsight being a necessity, the time interval between the moment of action and the moment of reminiscence needs to have been there to see it for what it is. Perhaps, then, every moment in photography can't not be a new origin, the beginnings of a "little history" on its own, ready to be inscribed upon by the future.

201206

\section{notes on photography 2}

In "The Heroism of Vision", Sontag describes the beauty of photography, essentially, comes from the fact that its unable to capture the beauty of the world for what it is, due to its limitations: she ends by stating that "the camera's ability to transform reality into something beautiful derives from its relative weakness as a means of conveying truth". For Sontag, photography, in suggesting a certain manner of seeing the world, becomes more prevalent than reality itself: reality becomes seen through photography, as "an array of potential photographs", leading the viewer further away from nature. Multiplicities of techniques that are outlined in the reading, whether it is extreme closeups of microcosmic worlds, pure pragmatic positivism, recreation of amateurism, or recording cruel social realities, all provide different ideas of what the photographer considers as beautiful, which can no longer merely be a mimetic representation of nature-- which used to be the ideal timeless image. Because the playing field is levelled-- the ease of access of the camera as an instrument consequently destroys the elitist, or restricted domain of the photographer as "artist"-- the average person, no matter the experience in theories or technical knowledge, can contribute to the creation of a photographic image. This democratizes the medium of photography: what used to be timeless and beautiful, in its manners of production, despite its uniqueness, gets levelled down-- simply because it could've been done by others in similar manners, there is less outstanding or that which stands the test of time. The project of deliberately being wrong, or a recreation of amateurism by the artist in negation of itself, paradoxically meeting artistic standards by deviating from it, also becomes a dead end, as there is no "inherent conflict between the mechanical or naive use of the camera". Fine art as photography is indistinguishable from amateur photography: "standards" are "democratized", there is a lack of necessity for high-art theories or formal techniques, as either, being indistinguishable, negates each other into the lowest common denominator. That which is levelled is not merely high-art and amateurism, but also conventional notions of that which is "traditionally beautiful": the "ideal faces" of fame, having been contrasted with the casualties of brutal social realities, "the anonymous, the poor, the socially defenseless...", brings out another notion of beauty from the lack thereof in a traditional manner. Before the eye of the camera, the distance between the brutal social reality is akin to the distance between the ideal faces of the traditionally beautiful, managing to level them down in the photographic world into the same position. That which is conventionally pleasing is contrasted against pictures of death, agony, "surreal standards of beauty... [akin to] Artaud's theatre of cruelty", and one finds out via the photographed, that two seemingly unrelated social realities, belong in the same world of images, which has taken over the images within the world. The contextual uses of the location of the photograph, "on a contact sheet, in a gallery, in a political demonstration..." can suggest the meaning itself, but what cannot be "secured" is an essence of the meaning of the photograph-- the meaning might as well having been utility itself, as per Wittgenstein. Such contexts, both immediate and subsequent, some photographs even being reutilized in other works of art, the essential meaning, as it gets further and further removed becomes more diluted. Captions as attempts to endow meaning, as the voice of the photograph, is inevitably also a limited interpretation due to the availability of the multiplicity of 
choices to attempt to describe the work as photograph. By consuming everything into the world of photography, but rejecting attempts at endowing meaning onto itself, photography "[converts] the world into a department store or museum-without-walls in which every subject is depreciated into an article of consumption". The "humanity" of photographs, for Sontag, is the levelling of all such situations down to a singular one-- the "quality things have in common when they are viewed as photographs". Through photographs, the world becomes a "tautology", the world isn't understood for what it is and how it actually is in reality, but is understood for what it becomes through the photographs. Photographed subjects are objectified, as they are not viewed as who they are, but what they become through the photograph, as much as photographed objects are given the same value as that which was originally a subject, having been photographed. Photography, then, makes things beautiful, not because it captures the world in its essence, but because it can't capture the world in its essence: its beauty, for Sontag, comes "from its relative weakness as a means of conveying truth". Photography freezes a moment in time, detaches it from reality, whether it be brutal social reality, a beautiful "ideal" face, political cruelties, etc. The "heroic" act might be taking reality out of itself, via the camera, to the world of photography, wherein the world is materialized and levelled democratically without the original meanings that were endowed within the world itself. The beauty of photographs, then, doesn't come from that which is, but that which can't be found within photographs: the world as it is.

\section{cindy sherman}

Douglas Crimp's reading explores the disappearance of Benjamin's "aura" in photography. Mechanical reproduction rid the notion of the original from photography, and representation took the place of the original. Crimp uses the work of Cindy Sherman to illustrate this: in her work, the presence of "Cindy Sherman" as representation completely takes over her as an original person. Trying to describe her work, Crimp writes: "Sherman is literally selfcreated.. in the image of... stereotypes; her self is therefore understood as contingent on the possibilities provided by the culture... it is a function not of presence but of absence, severed from an origin, from an originator, from authenticity... the aura has become only a presence, which is to say, a ghost" (p.34-36). What does Crimp mean by "a ghost"? For Crimp, attempts at restoring what was lost in mechanical reproduction only makes the whole situation worse, as the originality of the self becomes annihilated in the place of stereotypical self-creation amidst culture. As Sherman photographs herself, her image is not created, but selected from an already existing range of feminine archetypes that are present in her culture at the time. The aura of the self, then, is not only diluted via reproductions, but completely "severed"-- it is no longer possible to retrace the self back to what it used to be in nature, because culture has completely taken over its role. The aura's presence, or the uniqueness of the original self, Crimp says, is in our time that of a "ghost"-- meaning that its presence is diluted and concealed away from plain sight, because of the limited possibilities of self-creation within an already existing cultural paradigm.

\section{non-artist}

Jeff Wall's reading outlines the development of photography through the twentiethcentury, through photoconceptualism, the avant-garde, the art-photography, ending with amateurization. In amateurization, the artist acts as a non-artist, or plays the character of a social worker that has no interest in the arts. Consequently, the photograph itself is of less traditional aesthetic value, and in such reduction, it becomes replaceable, and almost negates itself. Trying to illustrate this process, Wall writes: "photography posits its escape... through the artist's performance as a non-artist... linguistic conceptualism takes art as close to the boundary of its own self-overcoming.... the philosophical content of aesthetics-- is experienced as the content of... enjoyment" (p. 359). What does Wall mean by "the content of enjoyment"? 
Traditionally, the content of enjoyment in photography used to be the sensuous experience, or generally the "aura", similar to the experiences that were carried over from the history of painting. However, photography, in trying to set itself apart, the artist behind the photograph is necessitated to act like his own negation-- a mere social worker. The photograph as art becomes replaceable, almost like a mere document, and the essay written about the photograph might as well replace the photograph itself, as much as the philosophical enjoyment replaces the sensuous traditional experience of the traditional aura. The "content of enjoyment", then, is that which has transformed and changed over time: from within the photograph as traditional enjoyment, to without the photograph as philosophical thinking.

\section{punctum}

Roland Barthes' reading explores the punctum, or the minor detail that Barthes believes is the essence of the photograph. Beyond the studium, or the cultural, historical, and semiotic meanings that are coded to be extracted within the photograph, Barthes defines the punctum as the unspeakable detail within the photograph that makes the photograph what it is. Barthes tries to illustrate the nature of the punctum by distinguishing the erotic image from the pornographic image. In differentiating the two, Barthes writes: "Pornography ordinarily represents the sexual organs, making them into a motionless object... the erotic photograph... may very well not show them at all... the punctum, then, is a kind of a subtle beyond-- as if the image launched desire beyond what it permits us to see" (p. 58-59). What does Barthes mean by "a subtle beyond"? The erotic, as opposed to the pornographic, conceals instead of revealing all within the frame of the photograph. The viewer of the photograph desires to see the punctum, or that which is present implicitly beyond the photograph. Paradoxically, the punctum, by being "subtly beyond" and not present within the frames of the photograph, endows the erotic image with its essence: the right amount of desire that leaves the viewer unfilfilled in a certain way, consequently giving the image its value. By making a minor detail of the erotic image an absence, the punctum launches an unfulfilled desire to see that which is "subtly beyond", which Barthes believes endows meaning and attachment of the viewer in a relationship with the photograph. 
precis: robert shaw, controlling darkness

https://journals.sagepub.com/doi/pdf/10.1177/1474474014539250

- in darkness, self is rendered more open to the other

- when the power to control darkness exists, the openness is more intimate than had the power been absent

- controlling darkness in the home is an act of power

- $\quad$ objective experiences of light and darkness in nature is different from subject experiences of light and dark in the household

- $\quad$ home can be either an emotional hearth of fear and isolation, or a place of retreatment of relaxation and protection

- $\quad$ darkness helps us be more open to the other-- to be affected by the other

- control over the ability to experience darkness in the home is the ability to have power over the experience of being rendered open to the other

- $\quad$ home is a multiplicity: what a home is to an immigrant worker can be different from a native-- an image of home depends on the personhood - imaginative and material

- activities in the home: either "care of the self" or "making", or reproduction of the home so that it is maintained properly

- $\quad$ the home at night has been explored in meaningful ways; in darkness studies, home was not important, but rather urban and public spaces were emphasized

- $\quad$ night merely offered an opportunity for homemaking not possible during the day

- $\quad$ merleau-ponty: darkness as permeation of the self

- minkowski: pathological disorientation in time is also spatial-- seems like two different expressions of the same disorder: dark spaces serve for such experience-- ego does not affirm itself in relation to darkness, but becomes confused by it, threatening sense of self

- bateson: identification of the self relies on the visuality of light

- deleuze: interaction of the self in the dark with objects and space is more vulnerable-both reduced in size, but expanded into a void

- relaxation:

- artificial lighting's effects on sleep-- power play of controling light and darknes sin the home

- $\quad$ comfortable sleep is for possible only throuhg a cultivation of a particular relationship to the world, one that controls the darkness in the home

- intimacy:

- $\quad$ people have sex during night

- $\quad$ night in the homes is a time for various forms of intimacy-- both romantic and erotic-subjectivity becomes increasingly mixed

- violence:

- $\quad$ night $\rightarrow$ openness to being affected by the other $\rightarrow$ connectino between the body and the world

- domestic violence more possible during the time of the night

- $\quad$ children are "tucked-in" etc

- when individuals do not have power of control of light and darkness-- affectivity can be dangerous

- $\quad$ conclusion-- home a mixture of light and darkness, power is established by the control of such, as much as the darkness can be illusive, the light can be illusive as well, darkness signals openness to alterity-- bringing both vulnerability and opportunity otherwise absent 


\section{notes on heidegger vs wittgenstein}

200126

- Wittgenstein responds to solipsism by posing it as a problem of language. For Wittgenstein, what the solipsist does is merely ignore conventional linguistic paradigms of a specific time and place. The meanings attributed to a word by those around them are not adhered to by the solipsist, instead, they choose to attribute their own meanings to words in place. The structures and meanings of language, and in turn the whole world for Wittgenstein, is rearranged in a manner that is particular to, and only to, the solipsist themselves. The difference in the self and the other is merely a difference in organizations of linguistic structures. Because the private linguistic paradigms of the solipsist and their uses of words is different from and cannot be accessed by the dominant public paradigm, any form of empathy and understanding is impossible for the solipsist.

- Reducing propositions in sentences to merely "expression of conventions" implies that there is no meaning in words other than which is attributed-- language isn't meaningful in of itself, but by means of utility. Language as a tool, as Wittgenstein suggests, is one way to look at language, but it shouldn't be the only way language is viewed-- because this hegemony of viewpoint is counterintuitive and merely recreates an encouragement for such "reductions" based on subsumptions that Wittgenstein advised against earlier. Morally troubling statements can also be deemed plausible if the uses of language is narrowed down as such.

- Discussions of ordinary language is useful in philosophy of language because it's good food for thought, and it's essentially an exposure of the base assumptions of the underlying hegemony. In thinking about what is dominant about ordinary "language games", one that we take for granted, it can also raise questions about the same kind of dominance in structures of politics, arts, etc. "Seeing" the contingencies of ordinary language can be difficult, but it seems to be a good exercise because it leads to possibilities of revealing the very same contingencies of dominant ordinary structures in other disciplinary areas.

- (66-67) -- differentiation of the use of "I" into subject / object + analogy

- In trying to reveal the activities of the solipsist, is Wittgenstein making an argument for / against solipsism?

\section{2}

- Just like attempts to explain principles of human behaviour with rats in a psychology lab is insufficient, language reduced to number of primitive uses is likewise insufficient. If one chooses to take on this task of reduction, no one would be able to stop it from happening. What will result from such tasks, however, seems to be a more limited view of language, hindered by arbitrary definitions, inevitably with subjective biases. The concept of "language games" in its entirety is contingent, and is merely one of many ways of viewing language. Imagining such games is good food for thought, but ideally it should just stay that way. - Wittgenstein debases the "transcendence" of the meaning of infinity by locating a particular use of the word in the context of his definitions of language games. He analyzes "closed" and "open" games, which are differentiated by the contents of the game being quantifiably limited or unlimited. The form of the game remains unchanged in both cases, what is different is the apparent complexity that results from the difference in quantifiable content. For Wittgenstein, there is nothing significant or otherworldly about meanings of such "open games", and likewise the meanings of "infinity".

- Getting to the essence of a distinctive mental activity is complicated-- as in attempts to strip away an activity to its bare necessities, what seemed necessary is not at all and what seemed contingent turns out to be necessary. There is a multiplicity of acts that can potentially constitute as reading. The best possible definition seems to return to the notion of "family resemblances" of these activities-- all reminiscent of each other, but without an absolute defining characteristic. What can be put to words is the impossibility of defining the essence of an activity, but in doing so it "shows" an idea that gives the idea of such essence. 
- pg 112 - \#69 - ????? what is he saying here

- Does Wittgenstein ever change his method? Does he ever think outside of the language games? If he did, what would it look like?

\section{8}

- Wittgenstein proposes that in meaning or intending a new general rule, along with it comes an infinite cases of applications of said rule in which the "meanings" of the rules carry over directly. Within the rules in itself are all cases of the application of the rule, or "future transitions" as termed by Wittgenstein. Investigations of the causal nature of the relationship between the understanding of the rule to its applications leads to an infinite regress of reasoning that shows us the lack thereof-- Wittgenstein comes to the conclusion that there is no reason to follow such rules as we do.

- Much like the "infinity" case from earlier in the brown book, the seemingly transcendent nature of intuition of the will, or voluntary action, is reduced within the games of Wittgenstein. "Volition" in itself can be reduced to one of two distinct binary states of action, one where voluntary understanding occurs, thoroughly explained via mechanisms. There is nothing extraordinary in the will, but it becomes one of two cases-- one where voluntary understanding exists, contrary to one where it doesn't. This reduction is successful in that it places something seemingly unexplainable into an explainable realm, but it is still insufficient in that the act of reduction dismisses the whole of such concepts as the "will" in favour of simplicity.

- "Comparing" and "emphasizing" are distinguished as different methods in observations of particularities. Emphasizing implies that the particular is complete in itself, no external content or context is necessary to attribute meaning to the particular. Comparing, on the other hand, is reliant upon external context and reference for attribution of meaning-- the particular in itself is therefore insufficient to give the whole picture. Missing this distinction can result in confusions of language games-- one can believe that the particular that is referred to is being emphasized, when in reality it is being compared with or against. However, such distinctions seem to be merely contingent-- the falsity of the argument might come from the fact that often observation cannot be distinguished into two neat methods, both exclusive of the other. There can be an overlap of multiple language games, wherein a particular is both emphasized and compared. - pg 185 - last two paragraphs

- In participating in the processes of reduction in language, is Wittgenstein making a statement for or against reductionism? Does he not reveal the falsities of reductionism in showing its impossibilities?

\section{2}

- The danger that Heidegger refers to in his exploration of language is one of methodization and objectifications, reducing its essential qualities, "suprasensous" nature to better fit the concerns of western metaphysics. In speaking about language, the possibilities of subsumptions within the present systems always lurks in trying to define what its essential qualities are. The danger is referred to in multiple points in the dialogue, when the pair remind each other of their passivities in their own processes. In its most general sense, a constant and conscious redirection of attention to the nature of the activity of dialogue seems to help both avoid such dangers of objectification.

- Such genuine communication between the philosophies of the east and the west would probably be much more complicated and difficult of a process than it would suggest at first glance. A mere subsumption of eastern thinking under the ideals of western thinking can be projected an illusory integration-- which would be the easiest way but equally the most insufficient way to go about it. There is also the problem of the one and the many-- where the dominant hegemony of western philosophy is contrasted with the multiple varieties of eastern thinking, which have different genealogies with different systems. A "universal" language game of philosophy wouldn't just stop at integration of the west and the east, but would have to find a way to incorporate african, middle eastern, and other philosophies of the world. The roots of each thought system would have to be traced back toward its origin, in which each of the 
complex metaphysical basis in different theologies would have to be mapped out, then somehow contrasted and integrated with the western system without running into such "dangers" of objectification. Ultimately, it would be doable, and attempts would be interesting, but it seems extremely difficult and complicated to "genuinely" do it justice.

- The no-play seems to be an illusory manifestation of nothingness via radical minimality, the removal of everything but the gesture itself, so that focus is directed towards the present gesture and the meaning of movement itself is amplified in a way that would not be possible had attention been divided and fragmented. All meaning, both attributed and in-itself springs from the gathering within the gesture. This can be analogous to the processes of reduction in phenomenology, of removal of such "backgrounds" in language so that its essential nature and processes can be examined to reveal the nature of language.

- self-reflexivity of the dialogue-- analysis of itself

200220

- For Heidegger, one can "undergo an experience" with language when it "happens to" them, or when they are in "submission to" language. This particular relationship seems to only happen with a certain mindset-- when the reader has given up resistance to the text, letting the text happen to them. Language, for Heidegger, is with an ability to transform the reader, through an experience that the readers have no control over. It is interesting to see the differences between Heidegger and Wittgenstein in this manner-- Wittgenstein sought to dominate language, to transform it according to his experiences, whereas Heidegger wanted to be dominated by language, to have himself transformed according to it.

- For Heidegger, poetry and thinking resides in the same neighborhood. They parallel each other and don't distinguish themselves, but are distinguished. The relationship itself, or Being, "says"-- language is a matter of saying in speech, or the voice of Being. Heidegger wants to draw us near to the nature of the experience of language via casual imageries such as "house" or "neighbourhoods" within allegories, stories that can even be read as fables. Constant imagination becomes necessary to understand his descriptions, and results in a more fruitful understanding of the nature of language, in a way that wouldn't have been possible had his language been more concrete and direct. Conventionalists sought to systemize the nature of language, whereas Heidegger wanted to explore it.

- A guide-word in these lectures is a definition to hold onto, a reference point that is initially confusing, but gains more and more clarity, resulting in more satisfaction from the reader. "The being of language: the language of being" is introduced as the guide-word early on in the third lecture, and Heidegger guides us through the nearness of poetry and thinking within neighbourhood of language, defines nearness as the same as saying, defines nearness as independent of time and space, explores the contemporary domination of time and space, then defines nearness as a state of being "face-to-face" independent of spatial-temporal realities-- leading back where he started to an exploration of the meanings of the same guideword. The guide-word itself hasn't changed, the reader's understanding has, the relationship of the reader to the guide-word has changed by the end. An experience seems to have happened when a phrase that seemed to be unclear and meaningless has gained meaning and clarity via the text.

- 106 - time times, space spaces

- Are there many different "neighbourhoods"-- or just one? What is Heidegger's relationship to-- if there is any-- structuralism? In what way are these lectures in themselves "an experience"?

\section{7}

- The differences between Heidegger and Wittgenstein is made more evident when we see the ways in which both philosophers frame their activity of investigation of language-- Wittgenstein calls it a "muddle", Heidegger calls it a "mystery". This can potentially be an insight into how each other views not only the nature of their work, but also how they view the world. Strangely enough, both seem to agree on the pertinence of language, for both revealing the nature of 
language would lead to an understanding of the world. Wittgenstein's "muddle" implies a labour of language akin to a toiling physical work, a business of sorts, in need of structuring to bring clarity onto it. On the other hand, Heidegger's "mystery" implies an investigation of sorts, a clearing that brings about said clarity, a search to that which is unspoken of. For

Wittgenstein, language, and consequently his world, can be "done away with", as a businessman might be done with his labours for the day. Heidegger's world is one that he has no control over, the mystery happens to him, he doesn't make it happen.

- Heidegger rejects both the synchronic approach of Aristotle and the diachronic approach of Von Humboldt, deeming them insufficient to reveal the true essence of language qua language. For Heidegger, Aristotle devised an "architectonic structure" of language, forcing a structure upon language that reduces the sign from something that shows to something that designates, resulting in a "stipulation" or an objectification of the sign, unnatural in its essence. Von Humboldt uses a diachronic approach, creating a dialectic of language as a synthesis of worldview, where the thesis is the labour of the spirit and the antithesis is the objects that are laboured upon. Heidegger also deems this insufficient, as it is merely a "historical-spiritual" reading, implying that it is subject to the ideologies of a particular time and place.

- Ereignis, or the event of appropriation, is the process whereby language becomes possible, a path from "saying" to "showing". It is both the way and the making of the way to the essence of language, a concept without which language wouldn't have its own "peculiar property". It is both a path of becoming of language from being, making itself possible, which is also the same path that leads back to the unknowability of the wholeness of language. The process of appropriation also has an effect on people-- as appropriation, or saying of language, is also an effect on those who say as much as it is an effect on what is being said. Although Heidegger believes that language in its total essence can't be grasped, appropriation seems to be the next best possible thing to help us see that which cannot be spoken of.

- pg 132 -133 - information theory / appropriation

- Isn't "framing" and "formalization of language" an inevitable process? What would a world without such a thing look like?

\section{4}

- Heidegger believes in these essays that the punctuations "speak" as much as the words do: a colon can "open something up" or pave ways for "announcements" from the poet. Apart from purely functional grammatical means, it can be important that poets give punctuations equally as much thought as what can initially seem a minimal change of punctuation can bring about unforeseen differences in the overall experiences of the poem. The "mystery of words" that the essay explores cannot exclude the importance of punctuations and its roles and functions.

- For Heidegger, "renunciation" is a sort of admittance of a certain impossibility, of reaching an absolute distinction or a truth about the mysteries of the word and consequently the processes by which a poem or a language "does its work". The reader will never be able to figure out why a poem works completely in its essence, but still understand that it does. Renunciation is the self-denial of pursuit, or direction of effort towards the mystery, as Heidegger understands that such efforts are ultimately futile. The mystery will never be unveiled in its totality, but in experiencing the mystery, it gets the reader "nearer" to it "in remoteness". The ultimate stance in this case seems to be a self-sacrifice, of the poet and the reader, towards this mystery, submitting oneself to that which cannot be spoken of, but merely shown.

- Heidegger consequently believes that the purpose of elegiac poetry is to explore the sadnesses and the melancholy nature of the impossibility of pursuit, and the renunciation that comes from the realizations of such impossibilities. Elegiac poems explore the self-sacrifice and unceasing devotional nature of the poet to language, or the poem, doubling in irony due to the fact that the poet realizes the futility of such attempts. What's important in an elegiac poem, then, is the fact of the mere attempt as the poem: the poet understands that his ultimate quest to understand the mystery of language is impossible, but the poem itself that details such impossibilities, is in essence a trial to unveil the mystery, an attempt to do what is known 
to be futile. Such poems become, then, both an admittance of futility and an attempt at what is futile-- and in its duality is the preservation of such human "will"-- to explore and preserve in spite of hardships.

- page 154-- "rich and frail"

- Are there similarities of ultimate stances of futility in early Wittgenstein and Heidegger? ("what cannot be spoken of..." / "renunciation")

200319

- Hermogenes, initially in the dialogue, believes that only "convention and agreement" justify namings in language-- there is no real reason why the names attributed are as so, one option is equally as valid as another, and interchangeable. The names as sign are symbolic, meaning that the relationship between the name that is attributed and the thing in-itself is purely arbitrary. It is implied, then, that Hermogenes, stating that "no name belongs to any particular thing by nature", believes that there is no thing in-itself for the person, place, or thing that the name is attributed to. An advancement and further refinement of Hermogenes' initial stances from this dialogue could possibly lead to Wittgenstein's claims-- the conventions of language being the world, and nothing objective in essence existing. Hermogenes' claims seem to be a foundation on which Wittgenstein had built his theories of language on top of-- it can be seen as a basis, or a starting point, two different manifestations of the same fundamental beliefs. - Plato believes that ideal forms, or perfection, exist in a separate realm for humans to get close to. In turn, there would be ideal forms of names, or representations that are objectively more closer to these ideals than others. The weaver as a profession must learn the skills of using the shuttle as an instrument to produce the web. Some webs would be closer to these higher ideals of perfection than others, and the more cultivated the skills of the weaver, the closer they would be able to get to these higher ideals of nature. Likewise, naming is a skill of rearranging language to reach the higher ideals and bring them to reality-- those who are skilled at "naming" would be able to tell well-crafted names from worse ones, the processes of cultivating well-crafted names, and so on.

- Hermogenes does not seem to care for higher truths, which Socrates is passionate about. Such higher truths, about perfection and language, are difficult to reach, but can be done so via "investigations" of truths from learned people, or sophists, or written material, like those of Homer. Ignorance in this case seems to be in Hermogenes a lack of passion, or an absence of such will to reach existing truths. Socrates protests against a certain kind of idleness, in which one refuses to give thoughts to, or participate in, the cultivation of higher knowledge.

- 399E-400C -- body and soul-- body as tomb for soul

- How much of this dialogue actually happened? How much of Hermogenes and Socrates is the actual person, or creations of Plato? Socrates attempts to reshape the beliefs of Hermogenes-- is this a skill cultivated?

\section{5}

- Although it would be difficult to gage the extent to which Heidegger would agree with Cratylus, most of Cratylus' position on language revealed thus far in the text seem to coincide with, fundamentally, Heidegger's views, albeit in different terms and theories. Cratylus believes in the inherent correctness of language that can be reached via practice, implying that language has a certain power over its users, who are striving to reach its essences. In a sense this concept can recreate "the way to" language that Heidegger strived for.

- Socrates' etymologies can be a very particular way of looking at language, an attempt at finding the "absolute definition" for a word by tracing a word back to its very origins-- both within history and fragmented phonetics. There does seem to be something contingent about it-- one inevitably works within a particular system that is in no way absolute (i.e. Greek), what a word might "mean" in one discipline or language might be loaded with different historical contingencies in another. Fragmenting a word and putting it back together-- treating parts of a word, single letters as equipped with meaning seems to be a helpful exercise, as additional depth and clarity is gained in such "deconstructions". Agreements are made within an existing 
system between Hermogenes and Socrates: both agree on historical roots and the truths in phonetics, but such conclusions reached might not be as absolute as they might make it out to be. It helps with gaining clarity within a particular system, but entire systems of etymologies can be deemed unstable within another system, or another language game.

- Hermogenes congratulates Socrates on his "progress" in $410 \mathrm{e}--$ possibly on "the way to language"-- to which he replies that he is "run away with". Socrates finds himself far along on that single path at great speeds, he finds himself "run away with" on the path, possibly implying that he has a hard time keeping up with his own progress. His will to progress here might have become hardwired to the point of being unconscious, where it has become second nature for him to progress along the path. He realizes that he is "not yet at [his] utmost speed", implying that his fullest capabilities are yet to be reached-- if such a thing is reachable. Socrates here might be implying that such growth of expertise in said "skill" is infinite.

- $413 a$ - justice / fire

- Socrates talks with Hermogenes for the former half, and then talks with Cratylus with the latter half-- how would it be different if the three of them engaged in a conversation for the entirety of the text?

\section{1}

- The character of Socrates as a synthesis guides the reader to compare the ideas of Cratylus to those of Hermogenes. What the reader inevitably finds is a sort of unfinished dialectic, where the question itself remains unresolved, leaving the ending seemingly unsatisfactory. The unsatisfactory nature of the content redirects the reader's attention to the form of the dialogue, wherein which resides both the conventionalities and the essences of language. The dialogue as form is a certain agreement of exchange between the two within the conversation, and the manner of progression within such form, or the motion and the countermotion of the dialogue, is Saying, which becomes Showing. Socrates at the end deems the theory of Heraclitean change "perhaps true, perhaps not", which is analogous to the dual nature of the seemingly contradictory-- both the essences and the conventions-- concurrently residing within language. Language becomes the medium of the change of content within changelessness of form (or vice versa), which cannot be said properly, but merely shown.

- Socrates guides the other participators "against the grain" of natural conversation, into unexplored territory. The irony lies in the fact that although Socrates leads the conversation into such unknowns, by the end, not much progress has been made in the logical content of the dialogue, seemingly deeming it futile. The unsatisfactory nature of the content redirects the attention to the form, from which the reader can find the answers of what "has happened" per se. The irony is the duality of happening and its absence. Both Wittgenstein and Heidegger follow similar methods, albeit in different manners-- where the author draws the reader to alienate themselves from that which they are familiar with-- language itself-- in order to reorient their understanding of the possibilities of the medium itself. The author leads the reader away from their original point only to lead them back to the initial starting point, the full circle gives them the illusory impression of nothing happening, when in reality their conceptions with the medium itself has changed.

- Higher knowledge of oneness of the seemingly dual can be accessed by going against nature and inevitably coming back to it. Language can be the medium of representation for such metaphysical truths.

- Language happens to thought and poetry.

- Language is nothing but conventions, and consequently a problem that needs to be solved. 


\section{baby one more time critical analysis}

What is really happening when a pop song reaches number one on the charts? What exactly constitutes this "event"-- a "pop star" releasing a "pop song"?

Britney Spears hit it big in the late 90s and the early 00s-- getting her start in Disney's The Mickey Mouse Club, she entered the pop scene, revived teen pop, and dropped numerous chart-topping singles. Surprisingly, after numerous media battles, family troubles, and public meltdowns, her career is still very well underway, playing shows and cameoing in movies. The most interesting product to examine in her career could be her debut single, or "...Baby One More Time", the song that led her to her stardom and marked her place as a household name in the 00s.

A pop song, much like a product of a brand, can be a multifaceted whole-- the musical material is engineered meticulously, the lyrics serve to create a certain image, often the song is accompanied by a music video that furthers the narrative. The fans have an idealized fictional version of the pop star that they project themselves onto, transmitted through various mediums, whether it be in music, music videos, live shows, or interviews. Inevitably, a pop star "does well" because of certain societal conventions that increase demand for a particular archetype. Previous archetypes that did well in the past can be revisited and reused, much like a prototype of a device being improved upon-- only there are no patents or legal systems in place to handle something as vague as "ideal archetypes".

A pop song, then, is an "event" in that it shows a particular instance of the narrative of the pop star-- an engineering of a fictional character within a fictional narrative that the fanbase can project onto and find themselves in. The character is created and preserved in time with various mediums. Analysis of each medium can help one get to the bottom of what is actually going on.

There are archetypes for musical forms and structures that do well. Structure-wise, "...Baby One More Time" follows a conventional pop structure that is still prevalent to this day, an intro, followed by two sets of verses and choruses, followed by a bridge, returning to the chorus, in its finality varying slightly. The reason why this form works might be multifold-- the dichotomy of the verse and the chorus, the semblance of variation created by the bridge, the assertion of the meanings in choruses via repetition, and so on. Within the musical form is content that is symptomatic to the times-- reasons for why such forms work can be found in societal conditions: short durationality as form can be a symptom of the lack of leisure time, resulting in a need to fit tension and release into the briefest amount of time possible.

In terms of musical content, listening to Britney raises even more questions about the state of music in a pop context. As music exits its contextual particularities and enters the pop sphere, a strange phenomenon starts to happen, in that it becomes dislocated more and more from a particular time and place. Cultural contexts become ready-mades, but are difficult to pinpoint to real instances. There are kitsch tropes in "...Baby One More Time" that symbolically refer back to the song itself: the iconic three-note piano motif that the song begins with, or the orchestral crash of sorts that it ends with. A mix-and-match of archetypal tropes that do well at the time are pulled together: the 2000 "Oops!... I Did It Again" is basically a sequel to her debut single, using variations of the same musical motifs that did well for "...Baby One More Time".

Still, how does “...Baby One More Time" sound in general? Funk might be a reference point, the piano bridge vaguely resembles classical music, the backing vocals and the keys make the chorus sound almost choral, or devotional. The dilutions of the pop-sphere make it difficult to see the cultural origins of the pop song. What stays in the listener's mind after 
listening is more the arbitrary symbolic motifs, which exist less to refer back to a cultural context, but to serve the fictional character of the artist. The orchestral hit that ends the song has no semblance of a real event in a place and time, but instead is an assertion of Britney Spears: the sound as symbol merely serves her fictional image within the cultural realm.

Pop lyrics are far from a poem that plays with and exposes the conventions of language, in that language is only exploited to serve the creation of the ideal character of the singer. Digging into Britney Spears' lyrics would help the listener understand the character of, and consequently the semblance of a real self of, Britney Spears, but not much else. "...Baby One More Time", lyrically, is a tragedy of dependency and devotion: of a woman to a man, of Britney Spears to her lover, and possibly, of Spears' real self to her fictional self. Spears sings from the semblance of her real self to her fictional self: "the reason I breathe is you... there's nothing that I wouldn't do". The object of interest, however, is unresponsive, out of reach: it leads her further into "[losing] her mind", into "loneliness" that's "killing" her. Spears still holds on to this object for her life, and "confess[es]" that she "still believe[s]" over and over again. Repetition of language, in this case, serves to solely assert propositions: by the tenth time around when Spears repeats "Oh baby, baby", the listeners are really led to believe in the helpless existence of this other childlike fictional self that Spears herself creates.

By linguistic and musical means, pop songs become a medium of projection. The listener can imagine themselves as the singer, or the object of desire that is being sung to. They can be either Spears' real self, or the self that she self-creates, or they can "listen in" on the destructive relationship. This sort of tragic self-destructive devotion to one's own image doesseem to sell well-- why are listeners drawn to such tragedies? When Spears sings "hit me baby one more time", to play the song over again, to reaffirm herself, and the listener, of the existence of such tragedy, why do we comply? Why do we secretly like it when pop stars' lives go array?

Often people in tragic stories serve as a general reminder of what not to do with ourselves: our real lives won't ever be as chaotic as Spears', we wouldn't ever have to deal with self-image in such a destructive manner in front of the widest audience possible. But on the other hand, maybe we're just like them in a way: perhaps we like it when pop stars stray away from their former selves because it reminds us of ways we have done the same in our lives, the way we have to constantly battle our own self-images in the processes of becoming what we don't want to. Such a battle, a universal one, is branded, commodified, and sold-- the more genuine the struggle seems, the more accessible it is to a mass audience, the better it does in the market.

A bored Britney Spears in class waits for the school bell in the music video, her song plays out loud while she and her classmates do choreography. Britney gets the teacher to dance to her song, sings in a fancy car, and dances alongside a basketball game. The school bell rings again, her peers run out and the video ends as it started: she is still bored in class, and the song in its entirety is revealed to be her imagination, almost as if none of it had ever happened. 


\section{On The Flea}

In actuality reality, nothing much happens in The Flea: a flea sucks the blood of a man and a woman before the woman kills it. It is only through symbolism that the flea gains meaning - if a reader were to be oblivious to the nature of signification the poem would be confusing and meaningless. Giving elaborate significance to the insignificant happened often in Renaissance love sonnets, as in Whoso list to hunt, Amoretti, or Astrophil and Stella, but not to the extent it is done in The Flea. As opposed to prior love sonnets, in which symbolism of love depicted the ideal courtly love and its relationships or lack thereof, symbolism in The Flea serves as a means to an end for the speaker. Revision. However good a writer you are, good writing requires revision. That means rereading and revising your writing as much as possible, to eliminate unnecessary verbiage (wordiness) and awkward phrasing. Without revision, it's likely that your words are not as precise as they could be and that your sentence makes a point but not as clearly or concisely as it could or should. The symbol is only meaningful if it achieves the purposes of the speaker - the seduction of the woman. The man and the woman's selfhoods combined are merely represented as an image when the flea "sucks" (3) their blood. The speaker, in hopes in actualizing their relationship, loads the flea with meaning: the flea becomes "you and I" (12), their "marriage bed" (13), killing it would be a "sacrilege" (18). As levels of intertextuality become almost absurd, the representation of their love with actuality is contrasted with each other, and the flea as symbol depletes itself, leaving the speaker to question what it meant - if anything at all. This is a promising intro with need for revision/ deletion at the opening. Intro 8/10

The Flea adheres to the conventions of the Renaissance love sonnets in that extended metaphors are used to compare love with something else, along with extreme exaggerations in the comparisons - bordering on being far-fetched, but using just enough rationality to bring the poem back down to earth. Good Unrequited courtly love becomes gradually more twisted over time as the nature of the relationship itself becomes scrutinized and translated into metaphors. In Wyatt's Whoso list to hunt, an imitation of Petrach's Rime 190, his love is like an exhaustive hunt for a deer that keeps running away. Spenser's Amoretti are sonnets of fatalistic devotion, which to the speaker only are meaningful once read by his muse. Sidney's Astrophil and Stella is in a similar vein, begging for pity and mercy from his muse, before the speaker realizes that he has to write from his heart (cite it). Romantic sonnets a bit prior to Donne, in a dramatic generalization, tends to write about writing itself, and in turn about how the poet means to acquire meaning in the poem: sonnets became gradually more and more selfreferential and means to a plea to a significant other from the perspective of the male courtly lover. Conceit gained more intertextuality and complexity, but the traditional forms of fourteen lines and the rhyme schemes were carefully adhered to and rarely broken. The form of the sonnet became more stable while the content began to question itself. Good.

The Flea takes the same perspectival This word works against clarity. Just say perspective. stance as what came before in love sonnets: a distraught speaker making a plea for love to his significant other. However, little to no other conventions remain: there are more significant departures of style both in form and content to be found. There are three stanzas of nine lines, and the traditional rhyme scheme found in earlier sonnets is no longer adhered to. The significant other actually appears in the poem as an active figure of action, whereas in the past she were to be more distant, unreachable, and an idealized figure. Furthermore, and most importantly, The Flea marks the end of the gradual transition of symbolism of love - from aiming to portray objective ideals of courtly love, to an instrumental means to an end for the speaker. The flea as symbol is less important in its portrayals of ideal love, but more important in that it serves the purpose of the author - his seduction of his significant other. It only gains meaning if its own purposes are achieved. The tendencies of transformation in the nature of 
symbolism of love - from a more objective depiction to an instrumental means - that were hinted at from Spenser and Sidney meets its logical conclusion in the complete reliance on symbolism in Donne. Ok. You're right here, but a little more specific textual engagement would help.

The first stanza in The Flea reads as a beginning of an argument: a consoling consolation of sorts, in efforts from the speaker to lure the woman into bed. The speaker symbolizes the flea as the representation of the relationship between the man and the woman - then trivializes the symbol, with his resulting argument being along the lines of: "If the representation of our relationship is this trivial and petty, why can't the actual relationship be as such?". A clearer nod to your thesis here would give this paragraph sharper focus on the goal. The flea "sucks" (3) both the man and the woman, with their "bloods mingled" (4). This irreversible process makes the flea as the representation of the combination of the two people. The symbol of the selves combined is nothing to be ashamed of - the speaker deems it not "a sin, nor shame, nor loss of maidenhead" (6), trivial and morally justified. The ideal relationship symbolized in the flea, and the relationship in actuality is then contrasted: he admits to jealousy of his own ideal world as he deems the act of the flea as "more than we would do" (9). There is a clear discrepancy between what the speaker wants and what he is being denied to- and the symbol of the flea is merely utilized to contrast the two different worlds of the representation versus the actual. The speaker doesn't try to hide his intentions, resulting in even more selfreferentiality. Thesis?

The woman has already had enough by the second stanza, as she tries to murder the flea. The conventional approaches of "pleas" to the female figure is the main theme of the second stanza, but instead of directing his pleas to the woman, he loads the flea as symbol, and consequently the representation of their relationship with more meaning, in hopes to actualize the symbol. You might mention the inherent humour here, which is also inventive. The desperation of the speaker is made clear when he deems the flea "you and I" (12), "our marriage bed" (13), and "our marriage temple" (13). In contrast to the previous stanza, where the flea as symbol was petty and of no significance, the speaker overrides his previous argument by doing the opposite: loading it with significance. In his own self-contradiction is signs of despair: fear of loss of the actual relationship. In his fits of despair, he goes on further to deem the act of the destruction of the symbol immoral: it would be three separate deaths and sins - the death of the speaker, "self-murder" (17) of the woman, and a "sacrilege" (18). The speaker continues to utilize the symbol to his advantage, but at this point, the woman is already onto what he is doing. Really, she's largely unaware, as the poet imposes his imagination upon this scene.

Even after the flea's death in the third stanza, the speaker still utilizes the death of the symbol itself as his final argument of seduction. In a "cruel and sudden" (19) act, the woman has murdered the flea, but nothing has happened: the speaker finds "not thyself nor me the weaker now" (24). Emph. on the ridiculous would help here. The world of representations is not the same as the world in actuality - no matter how much he himself wants to lead the woman to believe in its illusive nature by loading it with meaning, the two different worlds have no distinct effects on the other. He reveals the flawed nature of his own argument, and consequently the nature of symbolism, but the symbol of the flea is dismantled only to his advantage: the amount of "honour" (26) lost when the woman chooses to "yield" (26) to the speaker will be the equivalent of the amount of meaning in the "flea's death" (27)- none. He contradicts his former contradiction, deeming his whole argument useless, resulting in another argument born out of a negation of his previous arguments - which basically restates his initial statement: that she should go to bed with him. The symbol is merely a tool in this whole 
process to serve the speaker: it represents as a means to an end, but in itself is not of importance.

What Donne does in The Flea in essence can be is multifold: it reads like an argumentative essay that reveals the very nature of symbolism, or its lack of meaning in-itself. The three stanzas can be a triptych of arguments: the thesis that argues for triviality or the lack of meaning in the symbol of the flea, the antithesis that argues for the overabundance of meaning in said symbol, resulting in a big reveal that the symbol in itself is meaningless, affirming his initial point. Good. The process of self-destruction of both the speaker and his text is only his desperation for the woman. The woman, however, remains unconvinced, revealing the pettiness of his very attempts. It is self-referential, intertextual, and funny - and deviates from former traditions of the traditional sonnet form, whilst adhering to others such as the desperate pleas of the male speaker. In its derivative nature, in which Donne constantly plays with the expectations of the reader, are multiple truths to be found about the intentions behind giving significance to the insignificant, the consequences of that very action, and whether the world of representations accurately reflect the actual world.

Grade: 85 . This is a fine essay, Andrei. There are clear signs of forethought and revision about; some revision would help further. Do read the comments above, but this is good work.

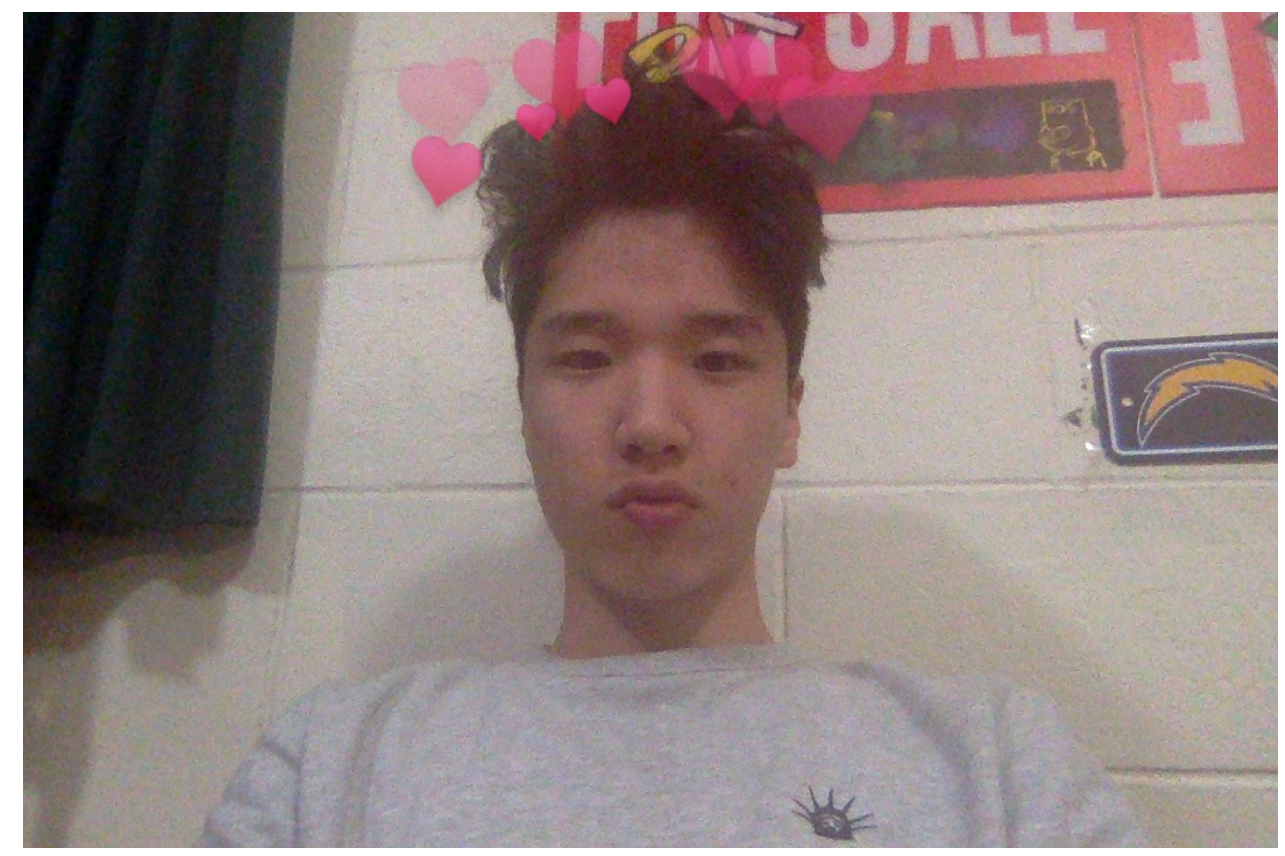

